\title{
Takotsubo syndrome or stress cardiomyopathy precipitated by severe myasthenic crisis
}

\author{
Síndrome de tako-tsubo o miocardiopatía por estrés desencadenado por una crisis \\ miasténica grave
}

\author{
Adrián Riaño-Ondiviela ${ }^{1 *}$, Javier Escota-Villanueva1, Guillermo Pinillos-Francia², Paula Morlanes-Gracia ${ }^{1}$, \\ Daniel Cantero-Lozano², Juan M. Salvador-Casabón ${ }^{1}$, and Arturo Andrés-Sánchez²
}

${ }^{1}$ Clinical Cardiology Unit, Cardiology Department, Hospital Clinico Universitario Lozano Blesa, Zaragoza; ${ }^{2}$ Clinical Cardiology Unit, Cardiology Department, Hospital San Pedro, Logroño. Spain

Myasthenia gravis is an autoimmune disease that affects the neuromuscular junction and causes generalized skeletal muscle weakness. The catecholaminergic discharges that appear in the context of increased physical or emotional stress generated in a myasthenic crisis can act as triggers of stress cardiomyopathy or takotsubo syndrome.

A 78-year-old woman with a personal history of high blood pressure, diabetes mellitus, and paroxysmal atrial fibrillation. She had been recently diagnosed with myasthenia gravis with positive anti-acetylcholine receptor antibodies. She was on outpatient treatment with pyridostigmine (30 mg every $8 \mathrm{~h}$ ) and prednisone (25 mg every $24 \mathrm{~h}$ ).

The patient attended the emergency department with an acute respiratory infection. At admission, clinical examination showed a decrease in strength of facial predominance, together with dysphagia, and progressive partial respiratory failure (baseline arterial blood gas test: $\mathrm{pH}, 7.43 ; \mathrm{pO}_{2}, 57 \mathrm{mmHg} ; \mathrm{pCO}_{2}, 37 \mathrm{mmHg}$; and $\left.\mathrm{SatO}_{2}, 92 \%\right)$. Starting treatment with intravenous immunoglobulin was decided at a dose of $400 \mathrm{mg} / \mathrm{kg}$ for 5 days plus respiratory support with non-invasive mechanical ventilation, with good initial evolution.

After 7 days' hospital stay, she had a new episode of acute respiratory failure with pulse oximetry desaturation of up to $80 \%$ despite high-flow oxygen therapy, which prompted orotracheal intubation and transferred to the Intensive Care Unit (ICU).

During the $1^{\text {st }}$ day of ICU stay, slight crackles were documented in both lung bases, and T-wave inversion in the entire precordial series was observed on the surface electrocardiogram. In addition, myocardial damage markers (high-sensitivity troponin T, $154 \mathrm{ng} / \mathrm{dL}$ and creatine kinase, $43 \mathrm{U} / \mathrm{L}$ ) elevation was detected, together with NT-proBNP increased values to up to $24,980 \mathrm{ng} / \mathrm{L}$. Although the patient experienced no chest pain anytime, an urgent echocardiogram was performed, which revealed slight left ventricular hypertrophy with moderate left ventricular systolic dysfunction (calculated ejection fraction: $35-40 \%$ ) due to akinesia of all apical and medial segments with basal segments hypercontractility (Fig. 1A). In view of these findings, an urgent coronary angiography was requested, which showed that epicardial coronary arteries were free of angiographic lesions (Figs. 2A and B).

Good respiratory evolution allowed early extubation at $36 \mathrm{~h}$. Neurological workup was completed with a chest $\mathrm{CT}$, which did not show thymus alterations that justified the episode. Control transthoracic echocardiography at 10 days indicated left ventricular systolic
Correspondence:

*Adrían Riaño-Ondiviela

E-mail: arondiviela@gmail.com 2604-7063 / @ 2019 Instituto Nacional de Cardiología Ignacio Chávez. Published by Permanyer. This is an open access article under the CC BY-NC-ND license (http://creativecommons.org/licenses/by-nc-nd/4.0/).
Date of reception: 11-03-2019

Date of acceptance: $24-04-2019$ 

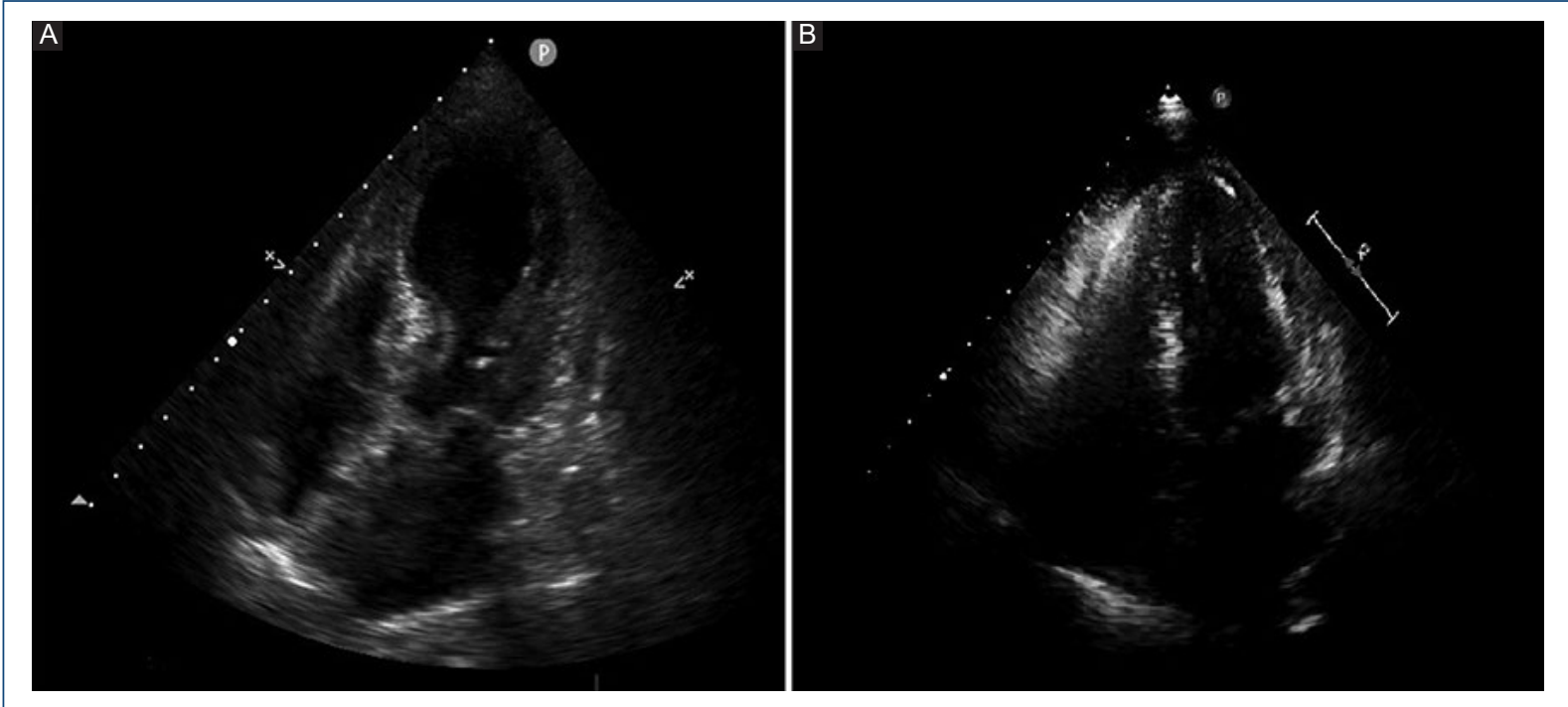

Figure 1. A: Apical window four-chamber transthoracic echocardiography performed in systole in the acute phase; akinesia of all apical and medial segments with basal segments hyper-contractility is observed. B: Apical window fourchamber transthoracic echocardiography performed in systole in the subacute phase, where contractility segmental alterations are not observed.

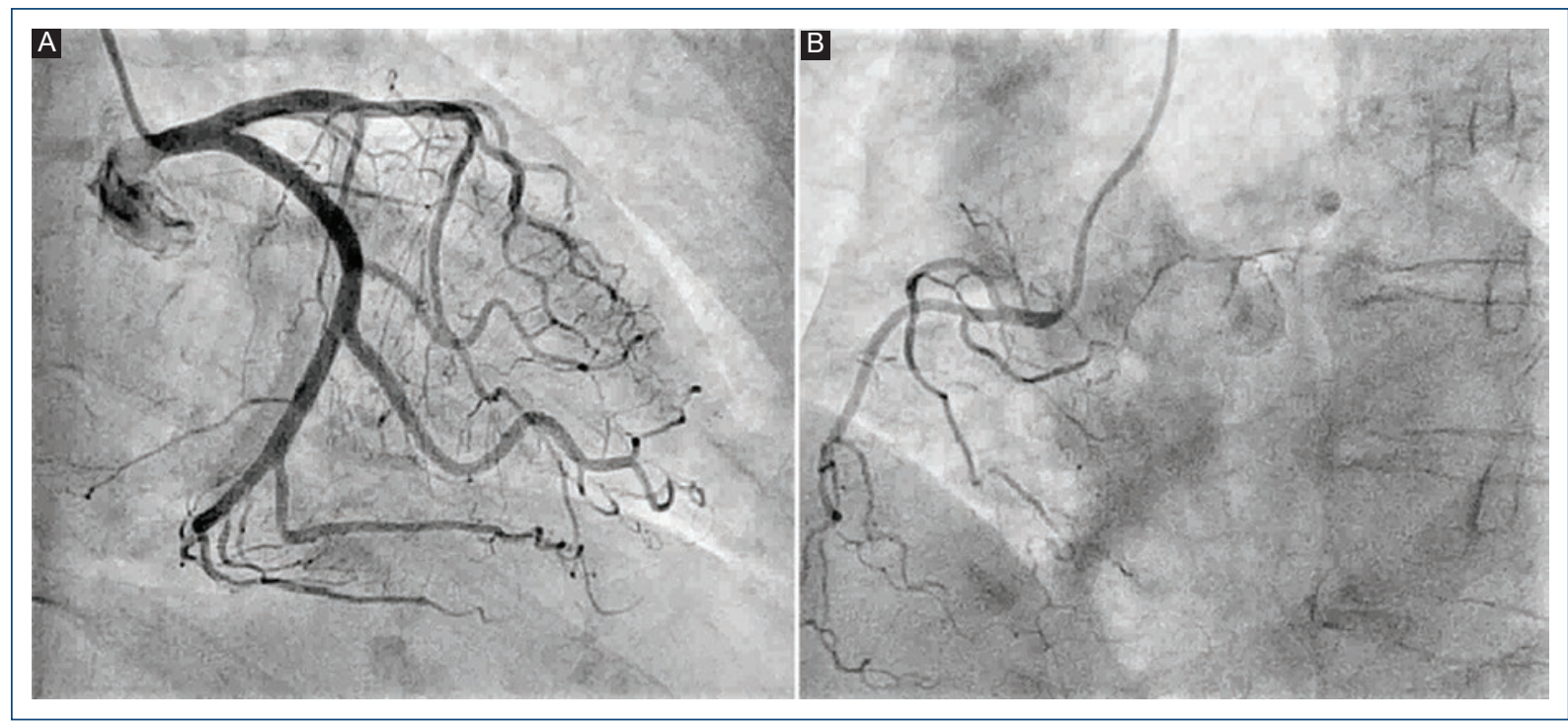

Figure 2. Diagnostic coronary angiography, where no epicardial artery filling defects consistent with ischemia, is observed.

function normalization ( $75 \%$ ejection fraction) and absence of segmental contractile alterations (Fig. 1B).

In addition, she had no arrhythmic episodes anytime. The described findings meet all InterTAK classification criteria for Class Illb transient apical dyskinesia, secondary to a severe myasthenic crisis that required orotracheal intubation.

Myasthenic crises are a highly unusual triggering factor of transient apical cardiomyopathy or takotsubo syndrome. In the literature, from 1970 to the present day, only eight cases of takotsubo syndrome caused by the severe myasthenic crisis and requiring mechanical ventilation have been described in the western world.

Myasthenia gravis is an autoimmune disease characterized by fluctuating muscle weakness due to a neuromuscular junction transmission disturbance. Patients with this disease can present myasthenic crises due to various causes such as infections, drugs, or 
other concomitant autoimmune diseases ${ }^{1}$. Recently, the InterTAK classification has been published, which groups takotsubo syndromes based on their triggering factors ${ }^{2}$. Although the mechanisms are not yet are clear, a marked relationship has been observed between high blood catecholamine concentrations and stress cardiomyopathy. Elevated values of adrenaline, norepinephrine, and dopamine, which are released into the blood flow due to stress (whether physical or emotional), can trigger reversible ventricular dysfunction during a myasthenic crisis in patients affected by this anomaly ${ }^{3}$.

In the presented takotsubo syndrome case, the absence of other potentially triggering causes, such as pheochromocytoma or hyperthyroidism, and the concomitant presence of a myasthenic crisis, make of the latter the cardiomyopathy precipitating factor ${ }^{4}$.

The relationship between both these entities makes for treatment to be complex. In addition, it is very important not losing sight of which drugs that are commonly used in cardiology should be avoided in patients afflicted by myasthenia since they could aggravate symptoms, such as Class 1a antiarrhythmic drugs (sodium channel blockers), given that they exert an anticholinergic effect. Other drugs that should be avoided include $\beta$-blockers, calcium antagonists, and quinidine $^{5}$. Due to the relatively low incidence of this syndrome and to its exceptional relationship with myasthenia gravis as clinical substrate, it is necessary to maintain a high suspicion index in the presence of non-specific symptoms or findings in these patients since they can compromise short-term prognosis, particularly in the acute phase ${ }^{6}$.

\section{Funding}

The authors had no funding.

\section{Conflicts of interest}

The authors declare that they have no conflicts of interest.

\section{Ethical disclosures}

Protection of people and animals. The authors declare that no experiments were performed on humans or animals for this investigation.

Confidentiality of data. The authors declare that they have followed the protocols of their work center on the publication of patient data.

Right to privacy and informed consent. The authors have obtained consent informed from the patients and/or subjects referred to in the article. This document is in the possession of the corresponding author.

\section{Acknowledgments}

The authors express their gratitude to Hospital Cínico Universitario Lozano Blesa of Zaragoza, especially to the Cardiology Department and to all colleagues who form it.

\section{References}

1. Wendell LC, Levine JM. Myasthenic crisis. Nuerohospitalist. 2011; 1:16-22.

2. Ghadri JR, Kato K, Cammann VL, Gili S, Jurisic S. Long-term prognosis of patients with takotsubo syndrome. J Am Coll Cardiol. 2018; 72:874-882.

3. Wittstein IS, Thiemann DR, Lima JA, Baughman KL, Schulman SP, Gerstenblith $\mathrm{G}$, et al. Neurohormonal features of myocardial stunning due to sudden emotional stress. N Engl J Med. 2005;352:539 (una sola página).

4. Prasad A, Lerman A, Rihal CS. Apical ballooning syndrome (tako-tsubo or stress cardiomyopathy): a mimic of acute myocardial infarction. Am Heart J. 2008;155:408-17.

5. Finsterer J, Stöllberger $C$. Stress from myasthenic crisis trigger takotsubo (broken heart) syndrome. Int J Cardiol. 2016;203:616-7.

6. Kato K, Sakai Y, Ishibashi I, Himi T, Fujimoto Y, Kobayashi Y. Predictors of in-hospital cardiac complications in patients with takotsubo syndrome. Heart Vessels. 2018;33:1214-1219. 